\title{
Creativity, Meaning, and Purpose: Mixing cultures in creative collaboration
}

\section{Mary Ellen Haupert, Ph.D.}

Professor of Music, Viterbo University

900 Viterbo Drive, La Crosse, Wisconsin, 54601

\begin{abstract}
Music composition is embedded into the Viterbo University music theory curriculum to promote active engagement of musical materials. The project accomplishes three basic complementary outcomes: 1) Students will be able to creatively apply and develop the foundations of music theory learned in their first year of university-level music study, 2) Students will develop proficiency using music writing software, and 3) Students will overcome their fear of composition and gain confidence as musicians. Students are taught foundational concepts during the first four semesters of music theory; these concepts are creatively applied and developed in the gestation and birth of a musical composition that is original and personal. Meaning and purpose, combined with guidance and encouragement, sustain these freshmen and sophomore students over a five-month process of framing a concept, composing music, editing their scores, and finally rehearsing and performing their works. The "concept" for the 2018-2019 freshmen and sophomore music theory students was a collaborative venture with Gateway Christian School, which is part of Project Gateway in Pietermaritzburg, South Africa. Poetry written specifically for this project by Grade 7 students was collected and given to Viterbo University students for setting. The student learning outcomes, as well as the global focus of the project are excellent examples of the value of high-impact teaching and learning.
\end{abstract}

Keywords: Music education, composition, project-based learning.

\section{Introduction}

High-impact teaching requires teachers who are dedicated to teaching beyond the information at hand. In order to make a vital connection with students, teachers must employ a variety of techniques to engage, encourage, and ultimately help students retain 
and make relevant connections with subject matter. This paper will present essential qualities for high-impact teachers and describe a class music composition project that offered students deeper learning in music, as well as a broader view of culture. The paper will also propose that high-impact projects such as the Viterbo University music composition project reinforce learning and build student confidence.

\section{Creativity, Meaning, and Purpose}

\subsection{Introduction}

Imagine yourself a ninth grader living in southern California on the first day of school. You seat yourself in the back of English 9 because you still haven't learned to spell and would prefer to stay unnoticed and uninspired. The bell rings and a handsome young man with a cool haircut and red tennis shoes walks into the door. He is funny, smart, and works hard to make a connection. You decide to pay attention.

\subsection{The Courage to Teach Creatively}

Matt Haupert was recruited (2013) by TEACH FOR AMERICA, a self-described "diverse group of leaders with a record of achievement who work to expand educational opportunity, starting by teaching for two years in a low-income community." ${ }^{1}$ He was hired to teach English at the Community Charter Early College High School in Lakeview Terrace, California, and although he doesn't have an education degree, he uses his background in theater and English to teach composition, literature, and poetry. He uses live turtles, humor, and any other manner of ingenuity to get his students excited about the material they are studying. In his words, "Today I gave my students the option of either sitting in their chairs or standing on their desks during our discussion of Lord of the Flies. One student's response: 'Well, gee, Mister...this class is sure abnormal!'”

\subsection{Engagement vs. Entertainment}

Engaging students at that level would have been criticized as "entertainment" when the author was a student thirty years ago. Back then, teachers received high marks for having instant recall and delivering an organized lecture (which is still commendable) and generally, cultivated a more objective approach to education. Thirty years ago, fine

\footnotetext{
${ }^{1}$ Teach for America: https://www.teachforamerica.org/our-mission. web
} 
teachers with a natural inclination toward presenting material in a creative and engaging way were more rare, especially in university settings. A few stand out. Retired Minnesota teacher Reuben Patnaude (Grand Rapids MN, School District \#318), was an art teacher who didn't believe in coloring books, so supplied his students (and children) with paper, paints, crayons, clay, and other materials for various class projects. Without controlling the outcome, he unfolded the principles of design, color, and texture in the same way that Matt approached a lesson on Lord of the Flies - out of the box.

At the collegiate level, master teacher Shelley Gruskin (College of St. Scholastica) made sure that each class period was a step into a world of possibility. ${ }^{2} \mathrm{He}$ went so far as to cobble together an Elizabethan-style masque, writing parts for each of his students in a staged public performance- unusual at a time when grasping the material didn't involve getting out from behind a desk.

Each of these teachers made an impact on the author of this paper, and their quest to make an indelible impact on each student's learning was achieved by the meaning and purpose they brought to the subject matter. In the same way that Reuben Patnaude aimed at refining the way that his students looked at the world (recognizing negative space and the nuances of artistic hues), the Viterbo University music composition ("Project Gateway" 2018-2019) was designed to help students experience music more as a creator than a consumer. Students involved in "Project Gateway" were given license to make an extraordinary amount of choices - affording them meaning and ultimate ownership of their creative work.

\subsection{The Soul of the Classroom}

In his book, "The Courage to Teach," Parker Palmer describes the ideal environment for teaching/learning as a community of truth that promotes living and learning in a purposeful manner. It is not enough to know things (which he describes as "objectivity") but to recognize that education, at its very best, pursues excellence through meaningful and purposeful relationships. He writes, "Teaching, like any truly human activity, emerges from one's inwardness, for better or worse. As I teach, I project the condition of my soul onto my students, my subject, and our way of being together."3

Viterbo student Alivia Schmidt-Sanders composed "Hide and Seek" as part of "Project Gateway." Her composition was based on a poem by Gateway Christian School $7^{\text {th }}$ grader, Munaste Chilembetembe. Alivia described the creative work that she did to capture the youthfulness of Chilembetembe's poem.

\footnotetext{
2 Zander, Benjamin and Rosamund Stone Zander. The Art of Possibility. Boston: Harvard Business School Press, 2000.

${ }^{3}$ Palmer, Parker. The Courage to Teach. San Francisco: John Wiley and Sons, 1998, 2007, 2.
} 
Basing my composition off the poem "Hide and Seek" by Munaste Chilembetembe was not only a great opportunity to get in touch with my creative side, but it was a chance to create something truly authentic inspired by my favorite kind of person, a child. Throughout the poem, the reader gets the impression of children at play, and I tried to capture that youthful feeling in my song. The melody of this piece is akin to the voices of children while they interact with each other. The song should make the listener feel like they are ten years old again, playing hide and seek with their friends in the backyard. The simplicity of the original poem allows for this time-travel to a simpler time in all of our lives where our only worry was staying quiet long enough to win a game of hide and seek. In a world full of hard challenges and tough decisions, it is always important to remember to live a simpler life like that of a child. ${ }^{4}$

\subsection{Fostering Intellect and Spirit}

Palmer claims that the greatest teachers are those who foster and develop intellectual, emotional, and spiritual aspects of the learning process in their students. His particular focus is one's "inner landscape" and writes about the type of outcomes that fully meet the demands of our global landscape. "To chart that landscape fully, three important paths must be taken - intellectual, emotional, and spiritual - and none can be ignored. Reduce teaching to intellect, and it becomes a cold abstraction; reduce it to emotions, and it becomes narcissistic; reduce it to the spiritual, and it loses its anchor to the world. Intellect, emotion, and spirit depend on one another for wholeness."

The "Project Gateway" music composition project incorporated the three important paths, described by Parker Palmer. The intellectual path involved compositional technique and software navigation, while the emotional and spiritual paths converged at times, but ultimately lay in the personal connections that each young composer made with his/her music compositions.

Student Zoe de Boer's "Spring Is Back," was based on a poem by Gateway Christian School $7^{\text {th }}$ Grader Siphokazi Hleta. Zoe's program notes convey the emotional and spiritual dimensions of music composition. The focus on Parker Palmer's "inner landscape" is evident:

I fell in love with the poem, "Spring is Back." The lyrics are so delicate and gorgeous. The language you [Siphokazi Hleta] used is mature and I think I was able to create a composition that showed the feelings that were caused inside my own heart when I read your [Siphokazi Hleta] poem. I have been deeply influenced by music performed at Feinstein's/54 Below, which is a very elite performance venue in New York City. I

\footnotetext{
${ }^{4}$ Program Notes, Viterbo University Music Department Forum; Friday, January 25, 2019.

${ }^{5}$ Palmer, 2.
} 
created a song that reflects something that could one day be performed there. I wrote rhythmic lines that mimic human speech. I am so excited to share my piece, using your voice with the world. ${ }^{6}$

\subsection{Best Practice in the Classroom}

Matt Haupert, Reuben Patnaude, and Shelley Gruskin are examples of teachers who espouse and engender creativity, meaning, and purpose in the classroom. They teach the subject-at-hand hoping that their students will use it for a greater purpose beyond the classroom. Like Parker Palmer, they convey passion for their subject matter in a way that becomes meaningful for their students. They provide us with "best practice" lessons that aren't narrowly focused on material, but include experience and reflection, while increasing possibilities in the classroom. Daniel Pink, in his book Drive, describes a necessary "third drive" that supports Palmer's intrinsic model: "The science shows that the secret to high performance isn't our biological drive or our reward-and-punishment drive, but our third drive - our deep-seated desire to direct our own lives, to extend and expand our abilities, and to live a life of purpose.",

\subsection{Generating a Spark of Possibility}

Conductor Ben Zander and his wife, Rosamund, incorporate creativity, meaning, and purpose into a practice they call enrollment. ${ }^{8}$ Mr. Zander works with high-achieving musicians at the New England Conservatory and abolished grading in his class because it increased anxiety and fear in the pressure-filled world of music performance. When they enter his classroom each week, they practice enrollment, described as "generating a spark of possibility for others to share."

Zander writes,

"We have at our fingertips an infinite capacity to light a spark of possibility. Passion, rather than fear, is the igniting force. Abundance, rather than scarcity, is the context. So the practice of enrollment is about giving yourself as a possibility to others and being ready, in turn, to catch their spark. It is about playing together as partners in a field of light. And the steps to the practice are:

1. Imagine that people are an invitation for enrollment.

2. Stand ready to participate, willing to be moved and inspired.

3. Offer that which lights you up.

4. Have no doubt that others are eager to catch the spark." ${ }^{\prime 10}$

\footnotetext{
${ }^{6}$ Program Notes, Viterbo University Music Department Forum.

${ }^{7}$ Pink, Daniel. Drive: The Surprising Truth about What Motivates Us. New York: Riverhead Books, 2009, 145.

${ }^{8}$ Zander, 125.

${ }^{9}$ Zander, 125.

${ }^{10}$ Zander, 126.
} 
Most of the students in the Viterbo University music department are singers who perform together regularly in choral ensembles and productions. Their collaborative work continually invites them for "enrollment" and participation in both performance and classroom activities. The "Project Gateway" composition project was no exception. Nathan Janzen's notes for his setting of Sthabile Ngoego's poem, "I Like Pizza," emulates the art of possibility that Zander describes in his work.

The poem I selected was "I Like Pizza" by Sthabile Ngeobo. The most attractive aspect of the piece to me was its short and sweet theme, which I decided to use ironically by putting it in a drawn-out operatic setting. I have really enjoyed working with this text and hope to see more works from this writer in the future. Sometimes the simple things in life are taken for granted - even the wonders of pizza and strawberries-but this experience with Gateway Christian School has not been one of those times. I would like to thank Shtabile and the staff of GCS and Viterbo for making this all possible. ${ }^{11}$

\section{Conclusions: The Challenges and Rewards of "Project Gateway"}

\subsection{Overcoming Obstacles}

Fear can be a formidable obstacle to creativity. The typical college music major memorizes part-writing rules and properly ascribes Roman numerals to musical excerpts from Bach to Berlioz, without ever writing a phrase of their own music. Many would prefer to reserve that work for musical geniuses like Mozart and Bartok. These "musical geniuses" exchanged ideas with one another and improved their performance and composition skills by creating and re-creating music (as well as requiring the same from their students). ${ }^{12}$

Today, there remains a shrouded mystique that reserves music composition for musical icons like Wolfgang Amadeus Mozart, Ludwig van Beethoven, Clara Wieck Schumann, and Amy Cheney Beach. In fact, the general lack of creativity in music education today has become an obstacle to music composition. Contemporary performers are more concerned with interpretation (adding fingering and other interpretative markings in performance scores) than they are with the creative process. Performers are expected to perfect what's in the score, but aren't required or even encouraged to perform their own original works. When students begin to compose, their experience more closely resembles that of the "musical geniuses," and ultimately changes the way they interpret music.

\footnotetext{
${ }^{11}$ Program Notes, Viterbo University Music Department Forum.

${ }^{12}$ Mann, Alfred. Theory and Practice: The Great Composers as Teachers and Students. New York: Norton, 1987, p. 7.
} 


\subsection{A New Way of Thinking}

The theory program at Viterbo University has been successful with various active-learning analysis projects, but there was significant improvement in the students' understanding of musical material when they began composing their own works. The idea was both personal and creative, yet required freshmen and sophomores to utilize what they learned in their respective theory classes. If they invested themselves in the project, there would be what Daniel Pink describes as the perfect "symphony." In his book, A Whole New Mind, the perfect symphony is "the ability to put together the pieces. It is the capacity to synthesize rather than to analyze; to see relationships between seemingly unrelated fields; to detect broad patterns rather than to deliver specific answers; and to invent something new by combining elements nobody else thought to pair."13

\subsection{Values - An Ocean Apart}

When Dr. Mary Ellen Haupert joined Dr. Matthew Bersagel-Braley, and a VUSM 300 (Viterbo University Mission Seminar) class in May 2018 on a trip to South Africa, she had no idea that the trip would provide the "concept" for the 2018-2019 music composition project. Even after collecting poetry from the $7^{\text {th }}$ grade English classes at Gateway Christian School/Project Gateway, and presenting the poems to Viterbo music theory students, there was still the risk that the project might fail.

Even so, it offered some powerful social and historical lessons to Viterbo students. Situated in a land that has been socially ravaged by apartheid, South Africa's Gateway Christian School/Project Gateway is committed to the education and training of children, young people and adults who would otherwise not have access to affordable, quality resources. Gateway Christian School/Project Gateway is also located in the "Old Prison" in Pietermaritzburg, South Africa, and contains a history museum with displays of political prisoners' Nelson Mandela and Mahatma Gandhi's incarceration. ${ }^{14}$ The cultural lessons were invaluable, even without the music.

\subsection{The Challenges of Distance Collaboration}

"Mixing cultures," from the start, was both difficult and exciting. Even though all the poems weren't set to music, there was a tremendous level of engagement from the music theory students. At the end of the fall semester, students submitted a working draft of their

\footnotetext{
${ }^{13}$ Pink, 130 .

${ }^{14}$ The Old Prison, Project Gateway, web.
} 
compositions, and at the beginning of the spring semester, students spent two weeks rewriting, editing, rehearsing and finally performing their works at the weekly music department forum. The performances were recorded and posted on YouTube so that our friends at Gateway Christian School could see the fruit of their work. ${ }^{15}$

Unfortunately, there wasn't an opportunity for a personal connection between each poet and composer. Though Gateway Christian School was happy to receive "Project Gateway" and share it with the teachers and students, we weren't able to facilitate conversations between each poet and composer, which might have brought deeper meaning to the process.

\subsection{Accomplishing a Goal}

Even without the personal connection between poets and composers, "Project Gateway" achieved its student learning outcomes. Students developed music theory skills while making choices about key, meter, melody, harmony, and rhythm; through their synthesis of musical elements, they became better interpreters of music. They applied elements of music to produce a work of art, while gaining proficiency with music writing software. They also gained confidence as musicians, while learning about the struggles and challenges of another culture. When the "Project Gateway" music theory compositions were performed at a Viterbo University Department of Music forum on Friday, January 25, 2019, the world seemed a bit smaller.

\section{Acknowledgments}

Thank you to Viterbo University Music Department, Matthew Bersagel-Braley (Viterbo University), Di Milford (Project Gateway - Gateway Christian School), and the Grade 7 teachers of Gateway Christian School.

\section{References}

Mann, Alfred. Theory and Practice (1987): The Great Composers as Teachers and Students. New York: Norton.

Palmer, Parker (2007). The Courage to Teach. San Francisco: John Wiley and Sons.

Pink, Daniel (2009). Drive: The Surprising Truth about What Motivates Us. New York: Riverhead Books.

Project Gateway: https://www.projectgateway.co.za/old-prison. web

\footnotetext{
15 It was bittersweet to receive word from Di Milford that our seventh grade poets matriculated to another school! Future collaborative projects with South Africa will need to partner poets and composers more intentionally.
} 
Teach for America: https://www.teachforamerica.org/our-mission. web

Zander, Benjamin and Rosamund Stone Zander (2000). The Art of Possibility. Boston: Harvard Business School Press. 